\title{
The Cyclicality of the Aging U.S. Motor Vehicle Fleet
}

\author{
Bill Dupor, Assistant Vice President and Economist
}

A merican car owners have been replacing their vehicles less frequently, causing the U.S. motor vehicle fleet to age (Figure 1). This article explores this phenomenon and the implications it has on auto manufacturing employment.

Figure 2 plots an index of the number of vehicles in use (green line) and an index of per capita new-vehicle sales (blue line). ${ }^{1}$ While the number of autos on the road has increased, (per capita) new-vehicle sales have been falling. This has occurred because the scrappage rate (i.e., the rate at which autos are taken out of use) has been falling. The fall in vehicle sales became more prominent starting in the mid-1980s.

Let's combine this fact with a second fact: New-vehicle sales typically fall dramatically during recessions (see Figure 2; gray bars indicate recessions), and did so both before and after the mid-1980s. What does this mean? First, when new-vehicle sales fall during a recession, the average age of the stock of autos in use becomes older. Following the recession, one of two things could happen. The stock of autos may become "young again" if there is a boost in new-vehicle purchases. Then, the average age of autos in use might be as young or younger than its prerecession level. Alternatively, the average age might remain higher following the recession. In this case, new-vehicle sales would not rebound nearly as much, which happened, most strongly, following recessions after the mid-1980s.

\section{More-reliable cars may have contributed to the slow rebound of auto sales and jobs after the past recession.}

Not surprisingly, these differential behaviors during the two periods have implications for employment dynamics in auto manufacturing. Figure 2 also plots an index of per capita employment in that sector (red line). Before the mid1980s, auto manufacturing employment moved closely with new-vehicle sales-employment tended to bounce back with sales. ${ }^{2}$ Then, the classic story was that workers laid off during a recession were brought back once the recession ended. But after the mid-1980s, sector employment does not bounce back as much. In fact, this later period is known

Figure 1

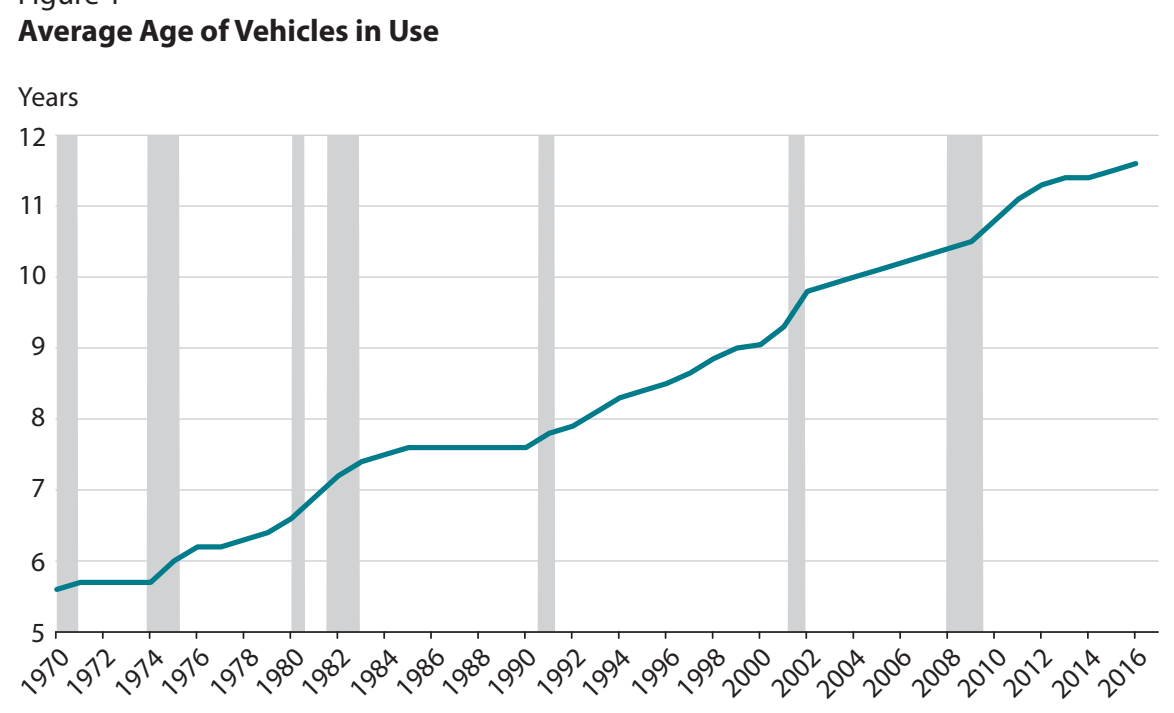

NOTE: Gray bars indicate recessions as determined by the National Bureau of Economic Research. SOURCE: U.S. Department of Transportation. 
Figure 2

Auto Sales and Employment

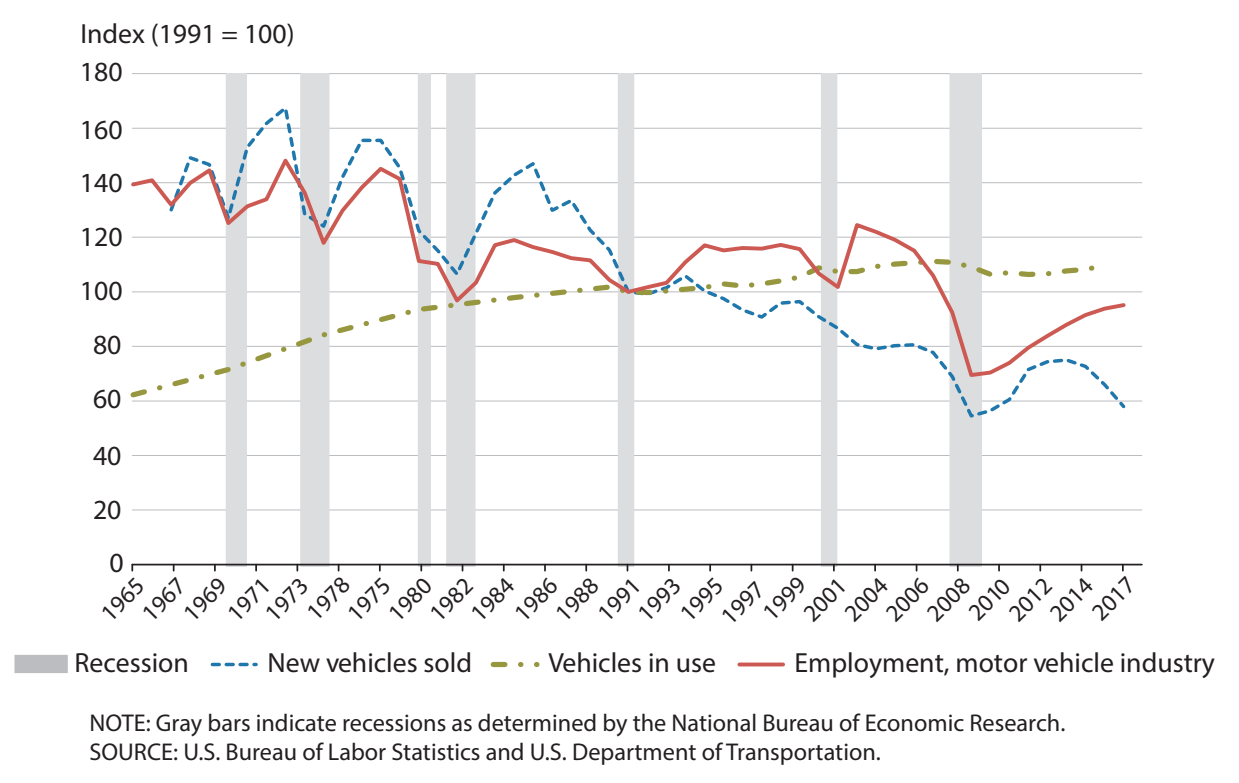

Figure 3

Year-to-Year Change in the Average Age of Autos in Use, Measured in Months

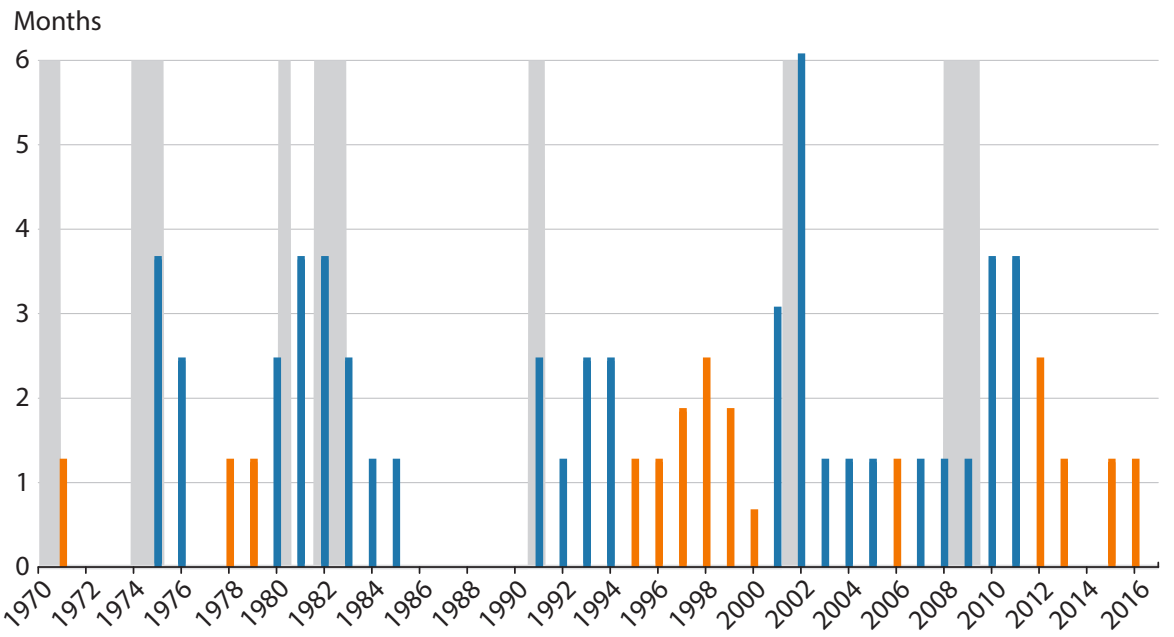

NOTE: Data are annual. Blue bars indicate either the year a recession begins or one of the four years that follow. Empty space indicates no change in the average age relative to the previous year. Orange bars indicate other years. SOURCE: U.S. Bureau of Labor Statistics and U.S. Department of Transportation.

as a time of "jobless recoveries." The changing dynamics of auto demand may be important for understanding jobless recoveries.

Figure 3 plots the change in the average age of autos in use relative to the previous year (measured in months), between 1971 and 2016. A year without a bar indicates no change in the average vehicle age. This value is nonnegative in every year and positive in most years.

There have been six recessions since 1972. As new vehicle sales fall during a recession, the average vehicle age rises. Bars marked with blue indicate either a business cycle peak year or one of the four years that follow. Orange bars indicate all other years. None of these recessions is followed by a rebound period where the nation's vehicle fleet becomes younger. If this were the case, then in at least one of these years, the plotted change in age would be negative.

Thus, the average age of the U.S. vehicle fleet has been trending upward over the past 45 years, with the trend temporarily accelerating in and following a recession. In 
the year of the business cycle peak plus the four years that follow, the average age of the fleet has increased by two months in each year. In the other years, the average age has increased by only one month.

Why have new-vehicle purchases not rebounded following recent recessions? One possibility may be, in part, that autos have become more reliable over time, suffering fewer breakdowns and costing owners less in repairs. Conjecturing further, auto owners may have followed a rule of thumb to purchase a new car, say, every four years. Once a negative shock-for example, a recession-forced the owner to hold a car for an additional year or two, he or she may have learned that the reliability of the car extended well into its fifth and sixth year-resetting the rule of thumb.

The new dynamics of auto sales, that is, slow and only partial improvement in sales, may thus be impacted by the fact that cars have become more reliable and less in need of repair. The slow recovery of auto sales following the last recession may, perhaps counterintuitively, have been affected by this improved reliability. For more on the auto market collapse during the past recession, see a recent Federal Reserve Bank of St. Louis working paper by Bill Dupor, Rong Li, Saif Mehkari, and Yi-Chan Tsai. ${ }^{3}$

\section{Notes}

1 Each variable in Figure 2 is measured in per capita terms.

2 The relationship is not close to one for one, most likely, for several reasons. The fraction of auto sales accounted for by production abroad trends upward during much of the period. Also, automation has reduced the number of workers needed on factory floors to produce a given quantity of cars over time.

3 Dupor, Bill; Li, Rong; Mehkari, Saif and Tsai, Yi-Chan. "The 2008 U.S. Auto Market Collapse." Working Paper 2018-19A, Federal Reserve Bank of St. Louis, September 2018. 